\title{
Partisipasi Masyarakat Desa Jungutbatu Di Daya Tarik Wisata Mangrove Tour, Nusa Lembongan, Kecamatan Nusa Penida, Kabupaten Klungkung
}

Pande Gede Kusuma Putraa, 1, Ida Bagus Suryawan, 2

pandeclownmask@gmail.com, ${ }^{2}$ idabagussuryawan@unud.ac.id

a Program Studi S1 Destinasi Pariwisata, Fakultas Pariwisata,Universitas Udayana, Jl. Dr. R. Goris, Denpasar, Bali 80232 Indonesia

\begin{abstract}
The Village of Jugutbatu has mangrove forest which is used as a tourist attraction. Mangrove forest itself has a function to minimize abrasion and tidal wave. Utilization of the attraction is inseparable from the participation of Jungutbatu villagers so this study aims to see the form of participation of Jungutbatu villagers in mangrove tour

This research uses observation, interview, and documentation techniques. This research uses qualitative data. Data source used is primary and secondary data source. Data analysis techniques in the form of narrative data exposure

Tourist attraction in newly discovered mangrove forest. Then the community began to plunge into the field of tourism by estabilishing mangrove tour organization sari segara serving mangrove tour services and making various tourism services such as restaurants, souvenirs, and alternative services around mangrove forests such as canoes, and standard paddle. Finally, public awareness to preserve the environment to create sustainable tourism
\end{abstract}

Keywords : Mangrove Tour, Participation, Local Community

I. PENDAHULUAN

Industri Pariwisata merupakan salah satu industri yang paling menjanjikan di era globalisasi seperti sekarang, industri pariwisata mampu meningkatkan pertumbuhan ekonomi dan menyediakan lapangan kerja, meningkatkan perekonomian, dapat meningkatkan standar kehidupan dan dapat mendukung industri - industri lain selain pariwisata. Industri lain yang dimaksut adalah seperti sektor kerajianan tangan, sektor perhotelan, sektor restoran, dan sektor lainnya (Salah Wahab, 1975). Pariwisata dapat meningkatkan perekonomian di suatu daerah sehingga banyak negara yang menjadikan industri pariwisata sebagai sektor utama, termasuk juga Negara Indonesia yang menjadikan industri pariwisata sebagai sektor untuk meningaktkan perekonomian di daerahnya dengan memanfaatkan kekayaan yang dimiliki seperti terdapat banyaknya keindahan alam yang membentang dari sabang sampai merauke, beragam warisan sejarah, budaya, dan kehidupan bermasyarakat. Salah satu industri pariwisata yang terkenal di Indonesia terletak di Pulau Bali.

Pariwisata Pulau Bali yang memiliki perbedaan dengan pariwisata di daerah lainnya menjadikan pariwisata di Pulau Bali memiliki ciri khas tersendiri, perbedaan tersebut terlihat jelas dengan adat istiadat dan tradisi masyarakat Pulau Bali, selain itu keindahan alam yang dimiliki oleh Pulau Bali berbeda dengan daerah lainnya. Pemanfaatan konsep
Tri Hita Karana yang lahir dari adat istiadat masyarakat Pulau Bali menimbulkan keselarasan dan keharmonisan yang terjadi antar masyarakatnya, baik itu hubungan baik antar manusia dengan Tuhan, antar sesame manusia, dan manusia dengan mahluk hidup lainnya.

Daya tarik yang terletak di Desa Jungutbatu, Pulau Nusa Lembongan berupa pemanfaatan hutan mangrove yang diberi nama Mangrove Tour. Hutan mangrove sendiri merupakan hutan yang berfungsi untuk menahan dari gelombang besar serta mengurangi adanya abrasi pantai yang diakibatkan oleh air laut. Hutan mangrove yang ada di Desa Jungutbatu pernah mendapatkan penghargaan Kalpataru sehingga ini mendorong masyarakat Desa Jungutbatu untuk lebih melestarikan dan menjaga hutan mangrove tersebut tetap terjaga.

Partisipasi masyarakat lokal sangat diperlukan dalam pengembangan pariwisata Mangrove Tour di Desa Jungutbatu karena dalam pengembangan pariwisatanya masyarakat lokal mengetahui keadaan sebenarnya yang terjadi di Daya Tarik Wisata Mangrove Tour. Mengetahui partisipasi tersebut sangat diperlukan untuk melihat seberapa besar partisipasi yang dilakukan oleh masyarakat lokal Desa Jungutbatu dalam Daya Tarik Wisata Mangrove Tour sehingga masyarakat lokal dan Desa Adat dapat melakukan peninjauan kembali sehingga 
pelaksanaan pariwisata yang ada menjadi maksimal.

\section{TINJAUAN PUSTAKA}

Penelitian ini menggunakan beberapa konsep dan teori, seperti :

1. Konsep Pariwisata merupakan suatu perjalanan dari daerah asal ke daerah tujuan dengan tidak ada tujuan untuk menetap di daerah tujuan dan bersifat rekreasi, menemukan pengalaman baru dalam berbagai kondisi yang dimana berbeda dengan daerah asal dari wisatawan (Kodhyat, 1983)

2. Konsep Daya Tarik Wisata memiliki 4 poin, yaitu :Attractions (Atraksi), Accessibility (Akses), Amenities (Amenitas), Ancillary (Organisasi pelayanan pariwisata) (Cooper, 1995).

3. Konsep Mangrove, mangrove merupakan hutan bakau yang memisahkan pantai dengan lautan lepas yang berfungsi untuk meminimalisir abrasi dan gelombang pasang. Berdasarkan pohonnya mangrove dapat disebut dengan hutan bakau dengan kadar garam 0,5 - 30 ppt (Arief dalam Ghufran, 2012).

4. Konsep Partisipasi Masyarakat. Tosun's Typology of Participation, 2006 yang dikemukakan oleh Tosun sendiri membagi partisipasi masyarakat menjadi 3 poin, yaitu :

a. Coersive Participation (Partisipasi Paksaan). Partisispasi ini masih bersifat paksaan, adanya pengaruh dari pihak luardan masyarakat menerima segala keputsan. Bersifat top-down.

b. Induced Participation (Partisipasi Terdorong). Masyarakat sudah memproleh hak tetapimasih bersifat tidak langsung. Bersifat top-down.

c. Spontanneous Pariticipation (Partisipasi Spontan). Masyarakat sudah diberikan hak untuk merencanakan pariwisata di daerahnya sendiri, dan sudah terlibat secara langsung. Bersifat bottom-up.

5. Butler, 1980 dalam Pitana, 2005 mengemukakan 7 siklus hidup pariwisata, tahapan tersebut yaitu : a. Tahap Eksplorasi (Explorasi). Ditemukannya pariwisata

b. Tahap Keterlibatan (Involvement). Mulai tersedianya fasilitas untuk wisatawan

c. Tahap Pembangunan (Development). Fasilitas sudah berstandar internasional. Pariwista yang ada sudah terbuka, adanya investasi ke daerah wisata dan promosi semakin sering dilakukan.

d. Tahap Konsolidasi (Consolidation). Di daerahnya pariwisata sudah menjadi industri utama dan pasar wisata telah mencapai pasar internasional.

e. Tahap Kestabilan (Stagnation). Pariwisata menjadi industri utama yang dimana semua telah tercapai sehingga menimbulkan masalah baru berupa masalah ekonomi, sosial, dan lingkungan. Pudarnya citra pariwisata pada tahap ini disebabkan oleh banyaknya atraksi buatan yang ada dan mengalahkan atraksi asli yang ada sehingga pariwisata tidak terkenal lagi.

f. Tahap Penurunan (Decline). Wisatawan mulai meninggalkan pariwisata di daerah ini dan menuju ke pariwisata yang lain. Fasilitas pariwisata yang awalnya untuk wisatawan beralih fungsi keaktivitas non pariwisata.

g. Tahap Peremajaan (Rejuvenation). Pariwisata yang terjadi pada trahap ini harus dibangun kembali agar pariwisata diminati oleh wisatawan kembali.

\section{METODE}

Lokasi penelitian yang dilakukan di hutan mangrove, Desa Jungutbatu, Kecamatan Nusa Penida, Kabupaten Klungkung, Provinsi Bali. Ruang lingkup yang digunakan adalah tiga poin yang dikemukakan oleh Tosun dalam Tosun's Tipology of Participation yang terdiri dari partisipasi spontan, partisipasi terdorong, dan partisipasi paksaan.

Jenis data kualitatif adalah jenis data yang digunakan dalam penelitian ini, seperti hasil wawancara, dan hasil partisipasi masyarakatnya. Selain itu data kuantitatif digunakan dalam penelitian ini berupa statistik 
luas hutan mangrove, jumlah penduduk, pekerjaan, dan kegiatan pariwisata di Mangrove Tour. Sumber penelitian yang peneliti gunakan berupa sumber data primer dan sumber data sekunder. Teknik pengumpulan data menggunakan empat metode, yaitu :1). Observasi dimana peneliti terjun langsung ke daerah yang diteliti dengan mengamati berbagai permasalahan yang ada baik dari segi sosial, budaya, dan fenomena alam yang kemudian dicatat. 2). Wawancara merupakan pengumpulan informasi yang dilakukan oleh peneliti dengan melalui percakapan secara langsung dengan informan yang memang dianggap berkompeten dan dapat memberikan informasi yang dibutuhkan dalam penelitian. Wawancara ini bertujuan untuk mendapatkan data primer dalam penelitian yang dilakukan dimana wawancara tersebut berdasarkan pedoman wawancara yang telah ditetapkan sebelumnya. 3). Dokumentasi merupakan suatu cara peneliti dalam melakukan penelitian dengan cara pengambilan foto atau gambar yang memang berkaitan dengan penelitian dan 4). Studi Kepustakaan merupakan teknik yang dilakukan oleh peneliti dengan cara menggunakan literature - literature sebagai refrensi dalam penyusunan penelitian ini.

Purposive Sampling digunakan dalam penelitian ini untuk menentukan informan yang nantinya akan digunakan sebagai sumber informasi. Purposive Sampling merupakan cara peneliti menentukan sejumlah informan dengan menentukan informan sebelum panalitian dilakukan, dengan menentukan informan yang nantinya akan di wawancarai sesuai dengan pedoman wawancara.

Penelitian yang peneliti lakukan menggunakan teknik analisis deskriptif kualitatif dimana teknik ini mempertimbangkan potensi yang ada yang kemudian di analisis dan dipaparkan dengan bentuk narasi. Ide yang ditemukan dilapangan kemudian diklarifikasi dan digolongkan sesuai dengan focus penelitian yang peneliti lakukan (Hendarso, 2007)

\section{HASIL DAN PEMBAHASAN}

Daya Tarik Wisata Mangrove Tour yang terletak di Desa Jungutbatu telah dikelola oleh masyarakatnya sendiri, sebagian besar masyarakat telah menyadari pentingnya pariwisata sehingga masyarakat lokal yang dulunya bermatapencaharian sebagai nelayan dan petani rumput laut mulai berpindah ke industri pariwisata. Sehingga partisipasi oleh masyarakat lokal dalam pengembangan pariwisata telah sekian lama dan dapat dirasakan oleh masyarakatnya sendiri. Adapun tahapan partisipasi yang dilakukan oleh masyarakat lokal Desa Jungutbatu dapat dilihat dari bentuk - bentuk partisipasi yang menjadi tiga tahap, yaitu :

1. Tahap Perintisan, pada tahap ini terjadi sebuah awal terbentuknya pariwisata yang ada di Desa Jungutbatu. Pada tahap ini masyarakat lokal Desa Jungutbatu yang dulunya bermatapencaharian sebagai petani rumput laut dan nelayan dan masih belum adanya kegiatan pariwisata yang ada di Desa Jungutbatu. Kemudian terbentuknya Daya Tarik Wisata Mangrove Tour karena adanya unsur ketidak sengajaan yang dimana saat itu ada salah satu masyarakat lokal Desa Jungutbatu bernama Pekak (Kakek) Jawa beserta Louis yang merupakan wisatawan dengan kewarganegaraan Perancis yang kebetulan pemilik dari Bunga Bungalow masuk kedalam hutan mangrove karena saat itu Louis ingin membuat peta hutan mangrove dengan cara mengambil gambar dari bagian atas hutan mangrove. Setelah mengambil gambar hutan mangrove tersebut Kakek jawa dan Louis melihat bahwa hutan mangrove tersebut memiliki aliran - aliran air yang saling sambung - menyambung. Kemudian mereka mencoba untuk mengelilingi hutan mangrove tersebut melalui aliran - aliran air yang mereka lihat, sehingga aliran - aliran air tersebut digunakan untuk jalur dalam mengelilingi hutan mangrove tersebut. Selanjutnya dilakukan promosi oleh Louis kepada wisatawan yang dating menginap di Bungalownya dank e negara asalnya sehingga hutan mangrove lebih dikenal lagi oleh wisatawan. Partisipasi yang terjadi pada tahap ini masih belum dirasakan karena masyarakat masih belum terjun ke industri pariwisata.

2. Tahap Pengembangan. Promosi yang dilakukan oleh Louis dan Kakek Jawa membuahkan hasil sehingga banyak wisatawan yang datang untuk berkunjung ke hutan mangrove 
tersebut sehingga ada antusias dari masyarakat lokal untuk terjun ke industri pariwisata. Pada awalnya masyarakat lokal mulai menyewakan jasa kepada wisatawan untuk mengelilingi hutan mangrove dengan sampan (perahu) yang mereka punya yang dimana dulunya sampan tersebut merupakan alat untuk bertani rumput laut dan mencari ikan. Karena pengembangan pariwisata yang mulai dirasakan adanya inisiatif dari Gunaksa yang saat itu merupakan Kepala Desa Jungutbatu yaitu memberikan ide kepada masyarakat untuk membuat kelompok yang dimana kelompok tersebut nantinya dapat mengelola hutan mangrove tersebut yang dimana kelompok tersebut sekarang bernama Organisasi Mangrove Tour Sari Segara.

Seiring berjalannya waktu pengembangan pariwisata yang terjadi di Mangrove Tour mengalami peningkatan sehingga untuk melakukan kegiatan mengelilingi hutan mangrove terdapat alternative - alternative lain seperti menggunakan kano, standard paddle, dan jasa penyewaan perahu bermotor. Selain itu terdapat juga beberapa fasilitas - fasilitas pariwisata yang diperuntukkan untuk wisatawan dan berdirinya toko cinderamata, restoran dan tempat menginap untuk wisatawan.

Partisipasi yang dilakukan oleh masyarakat lokal telah berjalan karena sebagian besar masyarakat sudah mulai terjun ke industri pariwisata, ini juga menyebabkan peralihan profesi masyarakat lokal yang awalnya sebagai nelayan dan petani rumput laut menjadi penyedia jasa pariwisata.

3. Tahap Pelestarian. Kesadaran masyarakat akan pentingnya menjaga lingkungan untuk menciptakan pariwisata berkelanjutan mulai dilaksanakan. Cara masyarakat dalam menjaga lingkungan dapat dilihat dari dua cara berikut, seperti :

a. Menjaga dan Pemeliharaan. Untuk dapat menjaga dan memelihara hutan mangrove dapat dilakukan dengan perluasan hutan mangrove dan rehabilitasi, serta Desa telah membuat awig - awig pada tahun 1983 yang dimana isinya adalah larangan kepada masyarakat lokal untuk memotong dan merusak tanaman mangrove kecuali untuk keperluan upacara. Organisasi Mangrove Tour Sari Segara juga melakukan kegiatan mangrove tour dengan cara tradisional yaitu perahu yang digunakan memakai galah untuk alat penggerak.

b. Pengawasan dan Sanksi. Organisasi Mangrove Tour Sari Segara melakukan pengawasan yang ketat untuk meminimalisir pelanggaran pelanggaran yang nantinya akan teerjadi di hutan mangrove. Pengawasan tersebut lebih ke pengawasan kegiatan kewisataan mangrove tour serta pengawasan lingkungan. Sanksi yang ditetapkan adalah bagi masyarakat lokal yang melanggar akan diberikan denda dan sanksi adat berupa tiga tahapan. Pertama kalau melanggar akan dimusyawarahkan ke dalam pertemuan desa, kedua jika masih melanggar akan diberikan sanksi berupa tidak akan mendapatkan ayahan banjar selama satu tahun, dan ketiga jika masih melanggar akan diberikan sanksi berupa tidak mendapatkan ayahan tingkatan desa selama satu tahun dan barang siapa yang tertangkap mencuri akan diberikan sanksi yaitu mengganti satu batang dengan seratus batang tanaman baru dan denda uang sebesar Rp 50.000,00

Tabel 1

Tahap Bentuk Partisipasi

\begin{tabular}{|l|l|l|}
\hline \multicolumn{1}{|c|}{ Tahap } & \multicolumn{1}{c|}{ Bentuk } & \multicolumn{1}{c|}{ Partisipasi } \\
\hline Perintisan & Ide & Terdorong \\
\hline Pengembangan & $\begin{array}{l}\text { Tenaga dan } \\
\text { uang }\end{array}$ & Spontan \\
\hline Pelestarian & $\begin{array}{l}\text { Pikiran dan } \\
\text { tenaga }\end{array}$ & Spontan \\
\hline
\end{tabular}

Sumber : Data yang diolah

Partisipasi masyarakat lokal Desa Jungutbatu yang telah melalui tiga tahap 
tersebut dapat dilihat bahwa partisipasi masyarakat yang awalnya bersifat terdorong hingga sekarang partisipasi masyarakat Desa Jungutbatu yang terjadi adalah Partisipasi Spontan

\section{SIMPULAN DAN SARAN}

A. Simpulan

Kesimpulan yang dapat disampaikan sesuai dengan pembahasan yang telah dikemukakan diatas bahwa terdapat tiga tahapan paritisipasi yang dilakukan oleh masyarakat lokal Desa Jungutbatu di Daya Tarik Wisata Mangrove Tour, yaitu :

1. Perintisan, pada tahap ini pariwisata baru ditemukan. Potensi - potensi wisata yang ada pada hutan mangrove baru ditemukan sehingga masih belum banyak wisatawan yang mengetahui tentang kegiatan wisata di hutan mangrove. Partisipasi masyarakat lokal pada tahap ini masih belum dirasakan

2. Pengembangan, pada tahap ini masyarakat mulai mengembangkan potensi - potensi dalam hutan mangrove untuk dijadikan daya tarik wisata oleh karena itu masyarakat yang awalnya bekerja sebagai nelayan dan petani rumput laut beralih ke industri pariwisata. Kemudian pada tahap ini juga terbentuk Organisasi Mangrove Tour Sari Segara yang dimana organisasi tersebut merupakan bentukan dari masyarakat lokal untuk lebih mengatur dan mengelola hutan mangrove sebagai daya tarik wisata. Pada tahap ini masyarakat yang bekerja di industri pariwisata bekerja sebagai penyedia jasa mangrove tour baik menggunakan sampan, kano, standard paddle, dan perahu bermotor serta restoran, toko cinderamata, dan penginapan.

3. Pelestarian. Pada tahap ini masyarakat yang sadar akan kelestarian lingkungan melakukan pengawasan, pelestarian dan penjagaan terhadap hutan mangrove serta memberikan sanksi sanksi kepada para pelanggar.

Pada tahap tersebut menjelaskan bahwa bentuk partisipasi masyarakat yang awalnya masih belum dirasakan hingga ke bentuk partisipasi yang bersifat spontan. Sehingga dalam tipologi yang dikemukakan oleh Tosun partisipasi masyarakat Desa Jungutbatu dalam Daya Tarik Wisata Mangrove Tour merupakan partisipasi spontan.

B. Saran

Berdasarkan pembahasan dan kesimpulan tersebut peneliti dapat mengusulkan beberapa saran yang dapat bermanfaat untuk kegiatan wisata di Daya Tarik Mangrove Tour. Saran yang dimaksut adalah sebagai berikut :

1. Kepada pemerintah. Masyarakat yang telah membentuk organisasi dan bahkan melakukan kegiatan dan tanggung jawab dalam pengembangan mangrove tour memiliki beberapa aspirasi - aspirasi yang perlu diwujudkan oleh pemerintah daerah setempat seperti usulan masyarakat tentang jaring - jaring sampah pada pohon bakau. Sehingga perlunya tindakan dari pemerintah daerah untuk merealisasikan hal tersebut yang dimana jaring - jaring tersebut penting untuk menjaga kelestarian lingkungan.

2. Terhadap masyarakat. Perlunya pelestarian yang serius sehingga lingkungan asri dan bersih dapat tercapai untuk mewujudkan pariwisata berkelanjutan.

\section{DAFTAR PUSTAKA}

Cooper, D.R. dan Emory, C.W. 1995. Business Research Methods. Irwin. United State

Ghufran, M. 2012. Ekosistem Mangrove Potensi, Fungsi, dan Pengelolaan. PT. Rineka Cipta. Jakarta

Hendarso, Emy Susanti. 2007. Penelitian Kualitatif : Sebuah Pengantar, dalam Metode Penelitian Sosial. Kencana Perdana Media Group. Jakarta

Kodhyat, H. 1983. Pengertian Pariwisata dan Kepariwisataan. Yogyakarta

Pitana, Gede. 2005. Sosiologi Pariwisata. Andi Yogyakarta. Yogyakarta

Setyadin, Bambang. 2005. Reduksi Data Melalui Analisis Faktor Eksplorastori

Tosun, C. 2006. Expected Nature of Community Participation in Tourism Development.

Wahab, Salah. 1975. Tourism Management. Tourism International Press. London 